\title{
P1 Biomechanical Properties of the Aortic Dissection Flap in Chronic Aortic Dissection
}

\author{
${ }^{1}$ University of Liverpool, Liverpool, United Kingdom \\ ${ }^{2}$ Liverpool Heart and Chest Hospital, Liverpool, United Kingdom \\ ${ }^{3}$ Keele University, Keele, United Kingdom
}

Phakakorn Panpho ${ }^{1}$, Hannah Davies ${ }^{1}$, Mark Field ${ }^{2}$, Jillian Madine ${ }^{1}$, Ying Yang $^{3}$, Riaz Akhtar ${ }^{1}$

\section{ABSTRACT}

Background: Aortic dissection is a devastating condition, beginning with a tear through from intima to the medial layer, leading to splitting of aortic layers and creating the false and true lumen with a septum (or flap). Little is known about the properties of the dissection flap.

Aim: To determine the time-dependent (creep) biomechanical behaviour and biochemical properties of the dissection flap.

Methods: 15 descending thoracic aorta samples were obtained from patients undergoing elective surgery for chronic dissected aneurysms. Creep was measured using a non-destructive ball indentation technique utilising a stainless-steel ball over 5 hours. Images were obtained using a long focal distance objective microscope. Remaining tissues were used to determine elastin and glycosaminoglycan (GAG) levels.

Results: The elastic modulus (tissue stiffness) was $64.68 \pm 11 \mathrm{kPa}$ and $55.1 \pm 9.5 \mathrm{kPa}$ for the flap and true aortic wall respectively. Over 5 hours, the central deformation of the flap tissue was found to be $0.52 \pm 0.07 \mathrm{~mm}$ as compared to $0.67 \pm 0.07 \mathrm{~mm}$ for the true aortic wall $(p<0.05)$. Elastin levels were $126.8 \pm 37.25 \mathrm{mg} / \mathrm{mg}$ for the flap and $79.82 \pm 19.64 \mathrm{mg} / \mathrm{mg}$ for the true aortic wall $(p<0.05)$. The GAG levels were $4.2 \mathrm{mg} / \mathrm{mg} \pm 0.9 \mathrm{mg} / \mathrm{mg}$ for the flap and $3.0 \pm 0.5 \mathrm{mg} / \mathrm{mg}(p<0.05)$.

Conclusion: The dissection flap exhibits reduced time-dependent deformation and has higher levels of elastin and GAG relative to the aortic wall. These findings may help develop bespoke surgical treatments based on the unique biomechanical and biochemical properties that have been identified.

(c) 2019 Association for Research into Arterial Structure and Physiology. Publishing services by Atlantis Press International B.V. This is an open access article distributed under the CC BY-NC 4.0 license (http://creativecommons.org/licenses/by-nc/4.0/). 